\title{
Regulation of the calpain and ubiquitin proteasome systems in a canine model of muscular dystrophy
}

\author{
Kristine M. Wadosky, B.S. ${ }^{1,{ }^{*}}$, Luge Li, B.S. ${ }^{1,{ }^{*}}$, Jessica E. Rodríguez, B.S. ${ }^{1}$, JinNa Min, Ph.D. \\ ${ }^{2}$, Dan Bogan, M.S. ${ }^{1}$, Jason Gonzalez, B.S. ${ }^{3}$, Cam Patterson, M.D. ${ }^{2}$, Joe N. Kornegay, \\ D.V.M., Ph.D. ${ }^{1}$, and Monte Willis, M.D., Ph.D. ${ }^{1,2}$ \\ ${ }^{1}$ Department of Pathology \& Laboratory Medicine, University of North Carolina, Chapel Hill, NC \\ USA \\ ${ }^{2}$ McAllister Heart Institute, University of North Carolina, Chapel Hill, NC USA \\ ${ }^{3}$ Department of Exercise and Sports Science, University of North Carolina, Chapel Hill, NC, USA \\ ${ }^{4}$ Department of Medicine and Pharmacology, University of North Carolina, Chapel Hill, North \\ Carolina
}

\begin{abstract}
Introduction-Previous studies have tested the hypothesis that calpain and/or proteasome inhibition is beneficial in Duchenne Muscular Dystrophy, based largely on evidence that calpain and proteasome activities are enhanced in the $m d x$ mouse.
\end{abstract}
Methods-mRNA expression of ubiquitin proteasome and calpain system components were determined using RT-PCR in skeletal muscle and heart in the golden retriever muscular dystrophy model. Similarly, calpain $1 / 2$ and proteasome activities were determined using fluorometric activity assays.

Results-We found that less than half of the muscles tested had increases in proteasome activity, and only one-half had increased calpain activity. Additionally, transcriptional regulation of the ubiquitin proteasome system was most pronounced in the heart, where numerous components were significantly decreased.

Discussion-This study illustrates the diversity of expression and activities of the ubiquitin proteasome and calpain systems, which may lead to unexpected consequences in response to pharmacologic inhibition.

\section{Keywords}

proteasome; calpain; muscular dystrophy; skeletal muscle; heart

\section{Introduction}

The muscle damage sustained in Duchenne Muscular Dystrophy (DMD) is cleared by two major proteolytic systems: the calpain and ubiquitin proteasome systems ${ }^{1,2}$.The

\footnotetext{
Corresponding Author: Monte S. Willis, M.D., Ph.D., McAllister Heart Institute, Department of Pathology \& Laboratory Medicine, University of North Carolina, Medical Biomolecular Research Building, Rm 2336, 103 Mason Farm Road, Chapel Hill, NC 27599-7525, Office: 919-843-1938, monte_willis@med.unc.edu.

Contributed equally to this manuscript.

Disclosures

None of the authors (K.W., L.L., J.R., J.M, D.B., J.G., C.P., J.K., M.W.) have any conflict of interest to declare.
} 
involvement of these proteolytic systems has prompted investigators to explore their role in the pathogenesis of DMD mainly using the $m d x$ mouse model ${ }^{2-14}$. At least 8 studies have tested the hypothesis that calpain and/or proteasome inhibition is beneficial in disease, and most have shown significant improvement in histology and function in short term studies (summarized in Supplemental Table 1 and Supplemental Table 2) 3-7, 10, 12, 13. Paralleling the therapeutic utility of calpain and proteasome inhibition on the $m d x$ phenotype, there has been the largely uniform evidence that calpain and proteasome activities are enhanced in DMD (Supplemental Table 1 and Supplemental Table 2).

These studies have been limited by their sampling of only 1 or 2 skeletal muscle types $(+/$ -diaphragm) and their use of the $m d x$ mouse model, which has a relatively mild phenotype compared to DMD in humans. We hypothesized that different muscle groups, including the heart, might have a more diverse expression and activity of calpain and the ubiquitin proteasome systems. If this is true, it might result in unexpected and possibly unintended consequences in response to calpain and proteasome inhibition. In this study, we investigated the diversity of proteasome and calpain activities in five representative skeletal muscles and the heart in the golden retriever muscular dystrophy (GRMD) model at six months of age. Despite the more severe disease phenotype in these animals, we found that only 1 (of 6) muscles had increased trypsin-like (proteasome) activity. In all 6 muscles tested, including the left ventricle, no differences in caspase-like and chymotrypsin-like (proteasome) activities were seen. Similarly, none of the 5 skeletal muscles or the left ventricle had significant increases in calpain $1 \& 2$ activities. Additionaly, transcriptional regulation of the ubiquitin proteasome system was most pronounced in the heart, where numerous components were significantly decreased, including the ubiquitin ligase CHIP, MDM2, and the E2 enzyme UNC4/5. The left ventricle also had decreased calpain 1 and calpain 2 expression, without affecting overall calpain $1 \& 2$ activities. These findings illustrate the muscle-specific differences in calpain and ubiquitin proteasome system expression and activity in GRMD, a DMD model that parallels human disease in many ways ${ }^{15-18}$. These findings illustrate how proteasome and calpain inhibitors used to treat DMD might have unexpected consequences that are muscle specific, particularly in the heart.

\section{Materials and Methods}

\section{Animals}

Dogs were cared for and utilized according to principles outlined in the National Institutes of Health Guide for the Care and Use of Laboratory Animals. Newborn GRMD dogs were identified based on elevation of serum creatine kinase (CK). Genotype was confirmed by PCR when CK results were ambiguous. Dogs subsequently developed characteristic clinical signs. Long digital extensor, lateral head of gastrocnemius, vastus lateralis, biceps femoris, cranial sartorius, and left ventricle of the heart were harvested from 7 GRMD and 8 control dogs at 6 months of age (Supplemental Table 3). Dogs were anesthetized using conventional preanesthetic drugs, propofol (normal dogs only), and sevoflurane. Of the 15 dogs, 12 were harvested after being euthanized, and 3 underwent biopsies before recovery and subsequent adoption (see Supplemental Table 3). The muscle(s) were exposed sharply at surgery to allow removal of a sample of approximately $1 \times 0.5 \times 0.5 \mathrm{~cm}$, snap frozen in liquid nitrogen, and stored at $-80^{\circ} \mathrm{C}$ for further processing. These studies have been approved by the University of North Carolnia Institutional Animal Care and Use Committee.

\section{Real time PCR analysis of UPS components}

Total RNA was isolated, cDNA was generated, and PCR products were amplified as described previously ${ }^{19}$. TaqMan probes were from Applied Biosystems, Inc. (Carlsbad, 
CA) and included dog specific probes for calpain 1 (Cf02704115_m1), calpain 2

(Cf02645870_m1), CHIP (Cf02644017_m1), MAFbx (Cf02667148_mi), MDM2

(Cf026759237_m1), MuRF1 (Cf02649993_mi), PSMA6 (Cf02666165_g1), PSMB4

(Cf01123846_m1), PSME1 (Cf02646187_g1), ubiquitin (Mm01622233_g1), UBC9

(Cf02655738_g1), UNC4/5 (Cf02657121_m1). Relative mRNA expression was normalized to 18S (Hs99999901_s1).

\section{Measuring 26S proteasome activity using fluorogenic substrates}

Assaying specific $26 \mathrm{~S}$ proteasome activities was performed as previously described ${ }^{20-22}$. Briefly, tissue was homogenized in lysis buffer $(250 \mathrm{mM}$ sucrose, $50 \mathrm{mM}$ Tris, $\mathrm{pH} 7.5,5$ $\mathrm{mM} \mathrm{MgCl} 2,0.5 \mathrm{mM}$ EDTA, $1 \mathrm{mM}$ dithiothreitol, 2mM ATP, and 0.025\% Digitonin). Approximately 25 micrograms of protein was added to the proteasome reaction buffer (50 $\mathrm{mM}$ Tris, $\mathrm{pH} 7.5,40 \mathrm{mM} \mathrm{KCl}, 1 \mathrm{mM} \mathrm{MgCl} 2,1 \mathrm{mM}$ dithiothreitol, $0.5 \mathrm{mM}$ ATP, and 0.05 $\mathrm{mg} / \mathrm{ml}$ bovine serum albumin) that contained fluorogenic substrates ( $75 \mu \mathrm{M}$ of Suc-LLVYAMC for Chymotrypsin-like activiy; $150 \mu \mathrm{M}$ of Boc-LRR-AMC for Trypsin-like activiy; $75 \mu \mathrm{M}$ of Ac-nLPnLD-AMC for Caspase-like activity) (Enzo Life Sciences International, Inc., Farmingdale, NY). Fluorescence was measured with a Wallace Victor 2 spectrophotometer (excitation $355 \mathrm{~nm}$, emission $460 \mathrm{~nm}$ ) 40 times every 2 minutes at $37^{\circ} \mathrm{C}$. Parallel samples were preincubated with the proteasome inhibitor epoxomycin $(20 \mu \mathrm{M})$ for $30 \mathrm{~min}$ at $37^{\circ} \mathrm{C}$ to determine the non-specific substrate hydrolysis. These fluorescence units were then subtracted from each measurement.

\section{Measuring Calpain1/2 activity using fluorogenic substrates}

Calpain 1/2 activity assays were performed using the Sensolyte ${ }^{\circledR}$ AMC Calpain Activity Flurometric Assay Kit according to the manufacturer's protocol (Anaspec, Inc, Fremont, CA). Briefly, calpain 1/2 activity in tissue extracts was assessed by hydrolysis of the fluorogenic peptide substrate succinyl-leucine-leucine-valine-tyrosine-4-methyl-7courmarylamide (Suc-LLVY-AMC). Fifty $\mu \mathrm{g}$ per well of tissue extracts were put into a 96well black opaque plate followed by the addition of the substrate solution. Fluorescence was measured using a GENios microplate reader (excitation $355 \mathrm{~nm}$, emission $442 \mathrm{~nm}$ )(Tecan Group Ltd., Durham, NC).

\section{Summaries of previous studies of muscular dystrophy, proteasome, and calpains}

Summaries of previous studies are summarized in supplemental tables $1 \& 2$. The studies were identified by searching PubMed using the search criteria indicated in the tables.

\section{Statistical Analysis}

A Rank-Sum test was performed, because most of the data were determined to be nonparametric using a normality test and (when appropriate) an equal variance test in Sigma Stat 2.03 (Systat Software, Inc, San Jose, CA). Statistical significance was set at P $\leq 0.05$.

\section{Results}

\section{Differential expression of the ubiquitin proteasome components is muscle specific}

The ubiquitin ligases MuRF1 and MAFbx/atrogin-1 have been prominently studied in skeletal muscle atrophy and are linked mechanistically to degradation of the sarcomere ${ }^{23}$. Their role in cardiac hypertrophy, atrophy, and metabolism has also recently been reported ${ }^{19,24-26}$. Therefore, we investigated their expression in the GRMD model. MuRF1 and MAFbx/atrogin-1 mRNA levels in GRMD did not differ from age-matched controls in all the muscles investigated (Figure 1A and 1B). The five GRMD skeletal muscles (long digital extensor, lateral head of gastrocnemius, vastus lateralis, biceps femoris, and cranial 
sartorius) generally had increased MuRF1 and MaFBx expression compared to controls, but these increases were not uniform.

Apoptosis has also been linked to the pathophysiology of DMD ${ }^{27-29}$. The ubiquitin ligases carboxyl terminus of Hsp70 interacting protein (CHIP) and murine double minute 2 (MDM2) have been reported to inhibit apoptosis by targeting $\mathrm{p} 53$ for degradation by the proteasome ${ }^{30-33}$. Furthermore, CHIP has been implicated in the pathogenesis of a Caenorhabditis elegans form of muscular dystrophy ${ }^{34}$. We therefore measured CHIP and MDM2 expression in GRMD. Both CHIP and MDM2 were signficantly decreased in the left ventricle (Figure 1C and 1D); MDM2 was increased only in the vastus lateralis (Figure 1D). Expression of CHIP and MDM2 did not significantly differ from control animals in the long digital extensor, lateral head of the gastrocnemius, bicep femoris, and cranial sartorius (Figure 1C and 1D). However, individual animals had increased CHIP and MDM2 in the biceps femoris and cranial sartorius. The expression of ubiquitin ligases in GRMD was largely unaffected in the skeletal muscles, while the downregulation of 2 of the 4 investigated in this study were seen in the heart, as summarized in Table 1.

To determine if expression of other UPS components are altered in GRMD, we measured mRNA expression levels of ubiquitin, uncoordinated phenotype 4/5 (UNC4/5), a protein chaperone involved in integrating myosin into the sarcomere ${ }^{35}$, and ubiquitin-like protein SUMO-1 conjugating enzyme 9 (UBC9), the sole conjugating (E2) enzyme for small ubiquitin-like modifer protein (SUMO) ${ }^{36}$. There were no differences in mRNA expression levels of ubiquitin between GRMD and control muscles (Figure 2A), consistent with a previous study in DMD patients ${ }^{8}$. UNC4/5 expression was decreased in GRMD left ventricle compared to controls, but it was unaffected in the five skeletal muscles (Figure 2B). UBC9 expression was significantly increased only in the cranial sartorius compared to controls (Figure 2C).

\section{Expression of proteasome subunits is significantly decreased in the GRMD heart}

We next determined the expression of 3 different proteasome subunits: PSMA6, PSMB4, and PSME1 (Figure 3). PSMA6 and PSMB4 are noncatalytic subunits of the 20S proteasome, ${ }^{37}$ and PSME1 is the alpha subunit in the activator heteroheptamer ring which binds to one or both ends of the 20S proteasome and allows peptides to enter the 20S subunit ${ }^{37}$. GRMD left ventricle had a significant decrease in the expression of all three proteasome subunits (Figure 3A-3C). PSMB4 was increased in 4 of the 5 GMRD skeletal muscles (Figure 3B). Expression of PSMA6 and PSME1 was unchanged in all GRMD skeletal muscles.

\section{Proteasome activity is generally unchanged in GRMD skeletal muscle and heart}

Using a fluorimetric assay, we assayed proteasome trypsin-like, caspase-like, and chymotrypsin-like activities from GRMD and control animals (Figure 4). The only significantly different proteasome activity in GRMD muscles was found in the lateral head of the gastrocnemius, with increased trypsin-like activity. Individual animals had increases in caspase-like and chymotrypsin-like activity in the gastrocnemius as well, but these increases were not uniform. Similarly, all three activities were increased in the long-digital extensor, but this was not uniform throughout the animals (i.e. not signficant). The disconnect between the decreased proteasome expression shown in Figure 3 and the unaffected proteasome activities is pronounced in the GRMD left ventricle (summarized in Table 2). 


\section{Calpain 1 and calpain 2 expression is decreased in the GRMD heart}

Calpains are $\mathrm{Ca}^{2+}$-dependent cysteine proteases which initiate the release of proteins from the myofibril, making myofibrillar proteins available for degradation by the UPS ${ }^{38}$. Calpain 1 ( $\mu$-calpain) and calpain 2 (m-calpain), so named because they are activated by micromolar and millimolar $\mathrm{Ca}^{2+}$ concentrations, respectively, are the most widely studied members of the calpain family and have been shown to be involved in the pathogenesis of $\operatorname{DMD}^{3,8}, 9,14,39$. Since we found that the UPS is altered in GRMD muscle, we next measured calpain 1 and 2 expression in GRMD. Both calpain 1 and 2 expression were significantly decreased in the GRMD left ventricle (Figure 5A \& 5B). Calpain 2 expression was increased in many of the animals in all 5 GRMD skeletal muscles, although only 3 muscle groups reach signficance (gastrocnemius, vastus lateralis, and cranial sartorius) (Figure 5B).

\section{Calpain 1\&2 Activity is not uniformly increased in GRMD skeletal muscles and heart}

Calpain $1 \& 2$ activity was not significantly different from age-matched controls in any of the skeletal muscles or left ventricle (Figure 5C). However, 4 of the 5 skeletal muscles and the left ventricle had individuals with increased calpain $1 \& 2$ activity, which did not reach significance.

\section{Discussion}

For nearly 2 decades, the role of intracellular proteolysis has been appreciated in DMD ${ }^{1}$. At least 8 studies have reported that calpain and/or proteasome inhibition is beneficial in

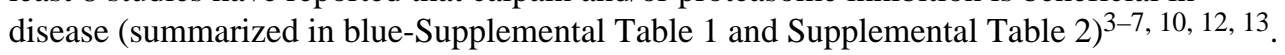
Paralleling the therapeutic utility of calpain and proteasome inhibition on the $m d x$ mouse phenotype, there has been largely uniform evidence in 4 studies that calpain and proteasome activities are enhanced in DMD (summarized in white-Supplemental Table 1 and Supplemental Table 2). What is striking about these studies is that they largely investigated short term proteasome and calpain inhibtion on mainly the milder $m d x$ muscular dystrophy in a very limited number of skeletal muscles, generally 3 or less. In this study, we investigated more broadly how muscular dystrophy in the GRMD model affected components of the ubiquitin proteasome system, the proteasome, and calpain activities (summarized in Tables $1 \& 2$ and the supplemental results section). While we detected increased proteasome and calpain activities in a minority of the muscles tested, we found that the heart had dramatically decreased expression of ubiquitin ligases (CHIP, MDM2), the proteasome (PSMA6, PSMB4, PSME1), and calpains (calpain 1 and calpain 2). This raises the concern that proteasome inhibition may inhibit proteasome and calpain activities in muscles that do not have increased proteolysis, and may potentially further inhibit muscles that have decreased expression of ubiquitin proteasome components and calpains, particularly the heart.

Inhibiting proteasome and calpain activities in muscles without increased activity is worrisome considering their diverse roles in the maintenance of the cell. This is a point that may have become obscured by the large number of studies that implicate these proteolytic systems in the degradation of specific substrate targets in the sarcomere ${ }^{40,41}$. The activity of the proteasome has been implicated at multiple points in the regulation of gene expression ${ }^{42}$. The $26 \mathrm{~S}$ proteasome specifically plays a role in modifying activators, co-activators, and corepressors of transcription necessary for gene transcription. Proteasome activity is also essential in numerous signaling pathways, including calcineurin, $\beta$-catenin, NF- $\mathrm{KB}$, and caspases, which are responsible for the regulation of cell death ${ }^{43}$. Similar to the proteasome, the calpain system plays diverse roles in cell biology. For example, calpains have been implicated in proliferation, differentiation, cell cycle progression, apoptosis, and cell 
signaling ${ }^{44}$. Calpain activity has been implicated in signal transduction through PKC, GSK-3 $\beta$, CaMK II and IV, myosin light chain kinase, and calcineurin (recently reviewed by Bukowska, et al. ${ }^{44}$ ). Calpains have also been implicated in the regulation of transcription factor regulation, including NF- $\mathrm{KB}, \mathrm{AP}-1$ (c-Jun/c-Fos), and c-Myc among others ${ }^{44}$. Given the diverse roles both the proteasome and calpains play in cell biology, inhibiting their activity broadly throughout all cells could potentially uncover many side-effects, at the very least, and potentially worsen outcomes.

Example of potential side effects come from experimental studies of proteasome inhibitors. Proteasome inhibitors are useful for the treatment of multiple myeloma, because they enhance cell death in myeloma cells ${ }^{45}$. How the heart may be affected by these therapies is just now starting to be appreciated. For example, inhibiting the proteasome in cardiomyocytes can induce cell death in cultured cardiomyocytes 46,47 and can adversely affect cardiac function in hearts challenged by pressure-overload ${ }^{48,49}$. In humans treated with proteasome inhibitors for multiple myeloma, ischemic heart disease complications have been reported ${ }^{50}$, raising the concern of systemic proteasome inhibition. The activity of calpains in cardiomyocytes has also been implicated in cardiac pathology ${ }^{44}$. While inhibiting calpains experimentally has been shown to reduce myocardial stunning, contractile dysfunction due to tachypacing, and damage due to atrial fibrillation, long term therapeutic benefits have not been studied ${ }^{44}$. For example, while calpain inhibition may inhibit apoptosis in some cardiac conditions, it is not clear if this is protective or induces alternative forms of cell death, namely necrosis ${ }^{51}$. Lastly, the complexity of interpreting all these studies is that DMD patients largely have an underlying cardiac defect caused by DMD itself. Specifically, most DMD patients exhibit dilated cardiomyopathy and ventricular arrhythmias due to their disease ${ }^{52-58}$, thus the heart has increased to further insult. This should raise concerns for unexpected side effects from inhibiting proteasome or calpain activity in a more complex milleu of DMD-related cardiac disease and should raise concern for testing these therapies in DMD patients.

Limiting factors in this study are the number of animals that were included and the variability seen in the GRMD disease model. While statistical differences were seen in 19 of the parameters tested, an additional 19 parameters had trends that were close, but not statistically different (summarized in Tables $1 \& 2$ ). The trends that did not reach statistical significance were likely due to the fact that this study utilized a limited number of highly variable samples. This variation makes it more difficult to delineate differences because of the heterogeneity of the population being studied. Despite these weaknesses, the major conclusions of this manuscript are largely not affected by these issues and allow us to show that both calpain and the ubiquitin proteasome systems are differentially regulated by different muscle types and are largely not increased.

Although we have emphasized the expanding role of the ubiquitin proteasome and calpain systems in diverse biological processes, they are best known for their roles in protein quality control in muscle ${ }^{40,41}$. Since widespread destruction of muscle and the sarcomere are involved in the pathophysiology of muscular dystrophy, inhibiting the destruction of damaged proteins may be one reason that proteasome and calpain inhibition have worked. By slowing the destruction of damaged sarcomere, more sarcomere is kept and used, despite its quality not being perfect. The buildup of post-translational modifications and reduced quality control could be the compromise needed to maintain function. However, the concern is not so much for the few skeletal muscles improved with proteasome and/or calpain inhibition. It is more for the heart, which in DMD patients is compromised to begin with and insulted further by inhibition of 2 of the 3 proteolytic systems necessary for maintenance of the cardiomyocytes. 


\section{Supplementary Material}

Refer to Web version on PubMed Central for supplementary material.

\section{Acknowledgments}

The work was sponsored by the Co-operative Program in Translational Research: Proposal for Establishment of the National Center for Canine Models of Duchenne Muscular Dystrophy (NCDMD) (1U24NS059696-01A1; NINDS) (to J.K.), the Muscular Dystrophy Association Infrastructure Grant to the Translational Research Advisory Committee (to J.K.), and the National Institutes of Health (1R01HL104129-01)(to M.W.).

\section{References}

1. Kamper A, Rodemann HP. Alterations of protein degradation and 2-D protein pattern in muscle cells of MDX and DMD origin. Biochem Biophys Res Commun. 1992; 189:1484-1490. [PubMed: 1482361]

2. Spencer MJ, Croall DE, Tidball JG. Calpains are activated in necrotic fibers from mdx dystrophic mice. J Biol Chem. 1995; 270:10909-10914. [PubMed: 7738032]

3. Badalamente MA, Stracher A. Delay of muscle degeneration and necrosis in mdx mice by calpain inhibition. Muscle Nerve. 2000; 23:106-111. [PubMed: 10590413]

4. Bonuccelli G, Sotgia F, Capozza F, Gazzerro E, Minetti C, Lisanti MP. Localized treatment with a novel FDA-approved proteasome inhibitor blocks the degradation of dystrophin and dystrophinassociated proteins in mdx mice. Cell Cycle. 2007; 6:1242-1248. [PubMed: 17495527]

5. Bonuccelli G, Sotgia F, Schubert W, Park DS, Frank PG, Woodman SE, Insabato L, Cammer M, Minetti C, Lisanti MP. Proteasome inhibitor (MG-132) treatment of mdx mice rescues the expression and membrane localization of dystrophin and dystrophin-associated proteins. Am J Pathol. 2003; 163:1663-1675. [PubMed: 14507673]

6. Briguet A, Erb M, Courdier-Fruh I, Barzaghi P, Santos G, Herzner H, Lescop C, Siendt H, Henneboehle M, Weyermann P, Magyar JP, Dubach-Powell J, Metz G, Meier T. Effect of calpain and proteasome inhibition on $\mathrm{Ca} 2+$ dependent proteolysis and muscle histopathology in the $\mathrm{mdx}$ mouse. FASEB J. 2008; 22:4190-4200. [PubMed: 18728218]

7. Burdi R, Didonna MP, Pignol B, Nico B, Mangieri D, Rolland JF, Camerino C, Zallone A, Ferro P, Andreetta F, Confalonieri P, De Luca A. First evaluation of the potential effectiveness in muscular dystrophy of a novel chimeric compound, BN 82270, acting as calpain-inhibitor and anti-oxidant. Neuromuscul Disord. 2006; 16:237-248. [PubMed: 16542837]

8. Combaret L, Taillandier D, Voisin L, Samuels SE, Boespflug-Tanguy O, Attaix D. No alteration in gene expression of components of the ubiquitin-proteasome proteolytic pathway in dystrophindeficient muscles. FEBS Lett. 1996; 393:292-296. [PubMed: 8814307]

9. Gailly P, De Backer F, Van Schoor M, Gillis JM. In situ measurements of calpain activity in isolated muscle fibres from normal and dystrophin-lacking mdx mice. J Physiol. 2007; 582:12611275. [PubMed: 17510188]

10. Gazzerro E, Assereto S, Bonetto A, Sotgia F, Scarfi S, Pistorio A, Bonuccelli G, Cilli M, Bruno C, Zara F, Lisanti MP, Minetti C. Therapeutic potential of proteasome inhibition in Duchenne and Becker muscular dystrophies. Am J Pathol. 2010; 176:1863-1877. [PubMed: 20304949]

11. Kumamoto T, Fujimoto S, Ito T, Horinouchi H, Ueyama H, Tsuda T. Proteasome expression in the skeletal muscles of patients with muscular dystrophy. Acta Neuropathol. 2000; 100:595-602. [PubMed: 11078210]

12. Selsby JT, Pendrak K, Zadel M, Tian Z, Pham J, Carver T, Acosta P, Barton ER, Sweeney HL. Leupeptin based inhibitors do not improve the mdx phenotype. Am J Physiol Regul Integr Comp Physiol. 2010

13. Spencer MJ, Mellgren RL. Overexpression of a calpastatin transgene in mdx muscle reduces dystrophic pathology. Hum Mol Genet. 2002; 11:2645-2655. [PubMed: 12354790]

14. Spencer MJ, Tidball JG. Calpain concentration is elevated although net calcium-dependent proteolysis is suppressed in dystrophin-deficient muscle. Exp Cell Res. 1992; 203:107-114. [PubMed: 1426033] 
15. Valentine BA, Winand NJ, Pradhan D, Moise NS, de Lahunta A, Kornegay JN, Cooper BJ. Canine $\mathrm{X}$-linked muscular dystrophy as an animal model of Duchenne muscular dystrophy: a review. Am J Med Genet. 1992; 42:352-356. [PubMed: 1536178]

16. Cooper BJ, Winand NJ, Stedman H, Valentine BA, Hoffman EP, Kunkel LM, Scott MO, Fischbeck KH, Kornegay JN, Avery RJ, Williams JR, Schmickel RD, Sylvester JE. The homologue of the Duchenne locus is defective in X-linked muscular dystrophy of dogs. Nature. 1988; 334:154-156. [PubMed: 3290691]

17. Kornegay JN, Tuler SM, Miller DM, Levesque DC. Muscular dystrophy in a litter of golden retriever dogs. Muscle Nerve. 1988; 11:1056-1064. [PubMed: 3185600]

18. Sharp NJ, Kornegay JN, Van Camp SD, Herbstreith MH, Secore SL, Kettle S, Hung WY, Constantinou CD, Dykstra MJ, Roses AD, Bartlett RJ. An error in dystrophin mRNA processing in golden retriever muscular dystrophy, an animal homologue of Duchenne muscular dystrophy. Genomics. 1992; 13:115-121. [PubMed: 1577476]

19. Willis MS, Ike C, Li L, Wang DZ, Glass DJ, Patterson C. Muscle ring finger 1, but not muscle ring finger 2, regulates cardiac hypertrophy in vivo. Circ Res. 2007; 100:456-459. [PubMed: 17272810]

20. Kristiansen M, Deriziotis P, Dimcheff DE, Jackson GS, Ovaa H, Naumann H, Clarke AR, van Leeuwen FW, Menendez-Benito V, Dantuma NP, Portis JL, Collinge J, Tabrizi SJ. Diseaseassociated prion protein oligomers inhibit the 26S proteasome. Mol Cell. 2007; 26:175-188. [PubMed: 17466621]

21. Kisselev AF, Goldberg AL. Monitoring activity and inhibition of $26 \mathrm{~S}$ proteasomes with fluorogenic peptide substrates. Methods Enzymol. 2005; 398:364-378. [PubMed: 16275343]

22. Min JN, Whaley RA, Sharpless NE, Lockyer P, Portbury AL, Patterson C. CHIP deficiency decreases longevity, with accelerated aging phenotypes accompanied by altered protein quality control. Mol Cell Biol. 2008; 28:4018-4025. [PubMed: 18411298]

23. Bodine SC, Latres E, Baumhueter S, Lai VK, Nunez L, Clarke BA, Poueymirou WT, Panaro FJ, Na E, Dharmarajan K, Pan ZQ, Valenzuela DM, DeChiara TM, Stitt TN, Yancopoulos GD, Glass DJ. Identification of ubiquitin ligases required for skeletal muscle atrophy. Science. 2001; 294:1704-1708. [PubMed: 11679633]

24. Li HH, Willis MS, Lockyer P, Miller N, McDonough H, Glass DJ, Patterson C. Atrogin-1 inhibits Akt-dependent cardiac hypertrophy in mice via ubiquitin-dependent coactivation of Forkhead proteins. J Clin Invest. 2007; 117:3211-3223. [PubMed: 17965779]

25. Willis MS, Rojas M, Li L, Selzman CH, Tang RH, Stansfield WE, Rodriguez JE, Glass DJ, Patterson C. Muscle ring finger 1 mediates cardiac atrophy in vivo. Am J Physiol Heart Circ Physiol. 2009; 296:H997-H1006. [PubMed: 19168726]

26. Willis MS, Schisler JC, Li L, Rodriguez JE, Hilliard EG, Charles PC, Patterson C. Cardiac muscle ring finger-1 increases susceptibility to heart failure in vivo. Circ Res. 2009; 105:80-88. [PubMed: 19498199]

27. Matsuda R, Nishikawa A, Tanaka H. Visualization of dystrophic muscle fibers in mdx mouse by vital staining with Evans blue: evidence of apoptosis in dystrophin-deficient muscle. J Biochem. 1995; 118:959-964. [PubMed: 8749313]

28. Sandri M, Minetti C, Pedemonte M, Carraro U. Apoptotic myonuclei in human Duchenne muscular dystrophy. Lab Invest. 1998; 78:1005-1016. [PubMed: 9714187]

29. Tidball JG, Albrecht DE, Lokensgard BE, Spencer MJ. Apoptosis precedes necrosis of dystrophindeficient muscle. J Cell Sci. 1995; 108(Pt 6):2197-2204. [PubMed: 7673339]

30. Tripathi V, Ali A, Bhat R, Pati U. CHIP chaperones wild type p53 tumor suppressor protein. J Biol Chem. 2007; 282:28441-28454. [PubMed: 17666403]

31. Haupt Y, Maya R, Kazaz A, Oren M. Mdm2 promotes the rapid degradation of p53. Nature. 1997; 387:296-299. [PubMed: 9153395]

32. Kubbutat MH, Jones SN, Vousden KH. Regulation of p53 stability by Mdm2. Nature. 1997; 387:299-303. [PubMed: 9153396]

33. Momand J, Zambetti GP, Olson DC, George D, Levine AJ. The mdm-2 oncogene product forms a complex with the p53 protein and inhibits p53-mediated transactivation. Cell. 1992; 69:12371245. [PubMed: 1535557] 
34. Nyamsuren O, Faggionato D, Loch W, Schulze E, Baumeister R. A mutation in CHN-1/CHIP suppresses muscle degeneration in Caenorhabditis elegans. Dev Biol. 2007; 312:193-202. [PubMed: 17961535]

35. Barral JM, Epstein HF. Protein machines and self assembly in muscle organization. Bioessays. 1999; 21:813-823. [PubMed: 10497331]

36. Desterro JM, Thomson J, Hay RT. Ubch9 conjugates SUMO but not ubiquitin. FEBS Lett. 1997; 417:297-300. [PubMed: 9409737]

37. Sorokin AV, Kim ER, Ovchinnikov LP. Proteasome system of protein degradation and processing. Biochemistry (Mosc). 2009; 74:1411-1442. [PubMed: 20210701]

38. Goll DE, Neti G, Mares SW, Thompson VF. Myofibrillar protein turnover: the proteasome and the calpains. J Anim Sci. 2008; 86:E19-E35. [PubMed: 17709792]

39. Saez ME, Ramirez-Lorca R, Moron FJ, Ruiz A. The therapeutic potential of the calpain family: new aspects. Drug Discov Today. 2006; 11:917-923. [PubMed: 16997142]

40. Willis MS, Schisler JC, Portbury AL, Patterson C. Build it up-Tear it down: protein quality control in the cardiac sarcomere. Cardiovasc Res. 2009; 81:439-448. [PubMed: 18974044]

41. Portbury AL, Willis MS, Patterson C. Tearin' Up My Heart: proteolysis in the cardiac sarcomere. J Biol Chem. 2011

42. Kwak J, Workman JL, Lee D. The proteasome and its regulatory roles in gene expression. Biochim Biophys Acta. 2011; 1809:88-96. [PubMed: 20723625]

43. Willis MS, Patterson C. Into the heart: the emerging role of the ubiquitin-proteasome system. $\mathrm{J}$ Mol Cell Cardiol. 2006; 41:567-579. [PubMed: 16949602]

44. Bukowska A, Lendeckel U, Bode-Boger SM, Goette A. Physiologic and Pathophysiologic Role of Calpain: Implications for the Occurrence of Atrial Fibrillation. Cardiovasc Ther. 2010

45. Testa U. Proteasome inhibitors in cancer therapy. Curr Drug Targets. 2009; 10:968-981. [PubMed: 19548862]

46. Tamura D, Arao T, Tanaka K, Kaneda H, Matsumoto K, Kudo K, Aomatsu K, Fujita Y, Watanabe T, Saijo N, Kotani Y, Nishimura Y, Nishio K. Bortezomib potentially inhibits cellular growth of vascular endothelial cells through suppression of G2/M transition. Cancer Sci. 2010

47. Fu HY, Minamino T, Tsukamoto O, Sawada T, Asai M, Kato H, Asano Y, Fujita M, Takashima S, Hori M, Kitakaze M. Overexpression of endoplasmic reticulum-resident chaperone attenuates cardiomyocyte death induced by proteasome inhibition. Cardiovasc Res. 2008; 79:600-610. [PubMed: 18508854]

48. Tsukamoto O, Minamino T, Okada K, Shintani Y, Takashima S, Kato H, Liao Y, Okazaki H, Asai M, Hirata A, Fujita M, Asano Y, Yamazaki S, Asanuma H, Hori M, Kitakaze M. Depression of proteasome activities during the progression of cardiac dysfunction in pressure-overloaded heart of mice. Biochem Biophys Res Commun. 2006; 340:1125-1133. [PubMed: 16403436]

49. Tang M, Li J, Huang W, Su H, Liang Q, Tian Z, Horak KM, Molkentin JD, Wang X. Proteasome functional insufficiency activates the calcineurin-NFAT pathway in cardiomyocytes and promotes maladaptive remodelling of stressed mouse hearts. Cardiovasc Res. 2010

50. Takamatsu H, Yamashita T, Kotani T, Sawazaki A, Okumura H, Nakao S. Ischemic heart disease associated with bortezomib treatment combined with dexamethasone in a patient with multiple myeloma. Int J Hematol. 2010; 91:903-906. [PubMed: 20458563]

51. Lendeckel U, Goette A. Calpain in atrial fibrillation: friend or foe?: editorial to: "anti-apoptotic effects of a calpain inhibitor on cardiomyocytes in a canine rapid atrial fibrillation model" by Yue Li et al. Cardiovasc Drugs Ther. 2009; 23:339-340. [PubMed: 19813082]

52. Finsterer J, Stollberger C. The heart in human dystrophinopathies. Cardiology. 2003; 99:1-19. [PubMed: 12589117]

53. Takami Y, Takeshima Y, Awano H, Okizuka Y, Yagi M, Matsuo M. High incidence of electrocardiogram abnormalities in young patients with duchenne muscular dystrophy. Pediatr Neurol. 2008; 39:399-403. [PubMed: 19027585]

54. Chenard AA, Becane HM, Tertrain F, de Kermadec JM, Weiss YA. Ventricular arrhythmia in Duchenne muscular dystrophy: prevalence, significance and prognosis. Neuromuscul Disord. 1993; 3:201-206. [PubMed: 7691292] 
55. Fauconnier J, Thireau J, Reiken S, Cassan C, Richard S, Matecki S, Marks AR, Lacampagne A. Leaky RyR2 trigger ventricular arrhythmias in Duchenne muscular dystrophy. Proc Natl Acad Sci U S A. 2010; 107:1559-1564. [PubMed: 20080623]

56. Megeney LA, Kablar B, Perry RL, Ying C, May L, Rudnicki MA. Severe cardiomyopathy in mice lacking dystrophin and MyoD. Proc Natl Acad Sci U S A. 1999; 96:220-225. [PubMed: 9874799]

57. Hsu DT. Cardiac manifestations of neuromuscular disorders in children. Paediatr Respir Rev. 2010; 11:35-38. [PubMed: 20113990]

58. Romfh A, McNally EM. Cardiac Assessment in Duchenne and Becker Muscular Dystrophies. Curr Heart Fail Rep. 2010

59. Kornegay JN, Cundiff DD, Bogan DJ, Bogan JR, Okamura CS. The cranial sartorius muscle undergoes true hypertrophy in dogs with golden retriever muscular dystrophy. Neuromuscul Disord. 2003; 13:493-500. [PubMed: 12899877] 
A Muscle ring finger-1 (MuRF1)
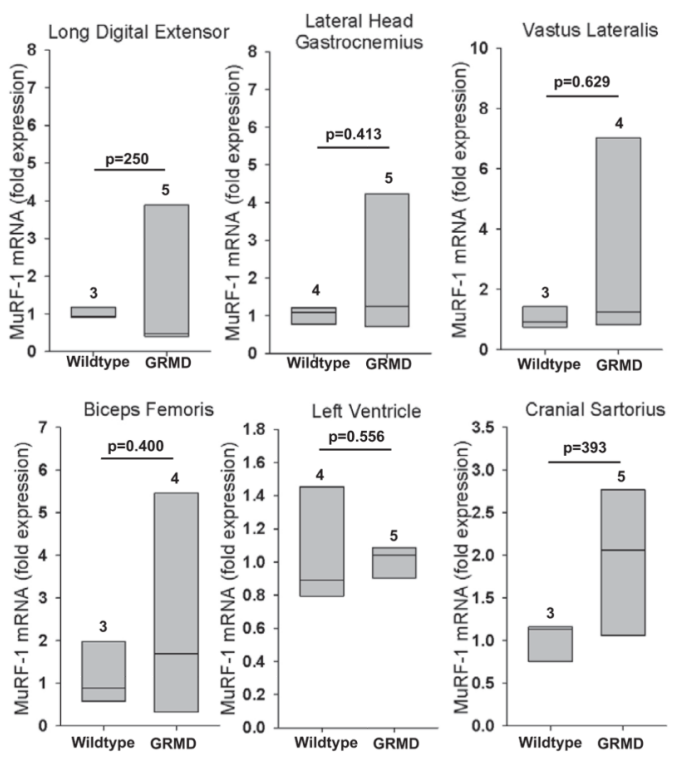

\section{Carboxyl terminus of Hsp70}
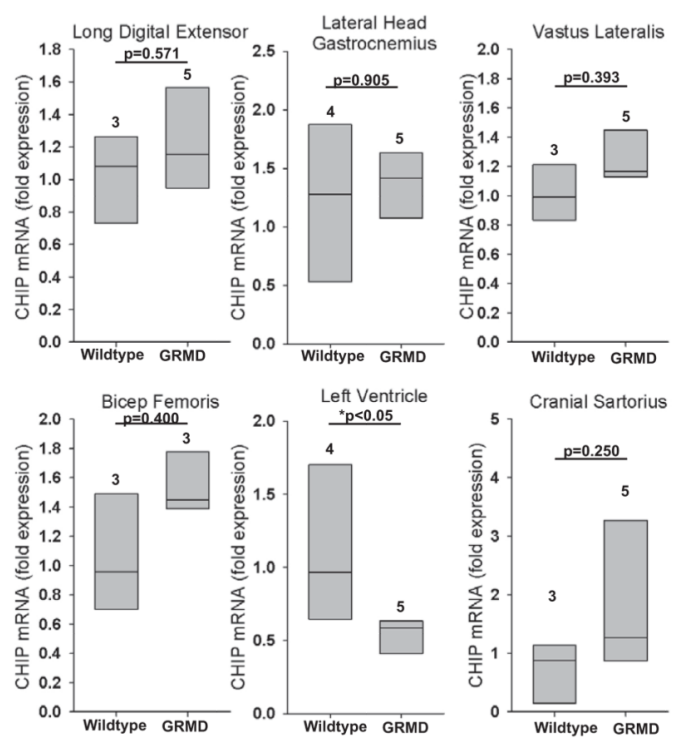

B MaFbx/atrogin-1
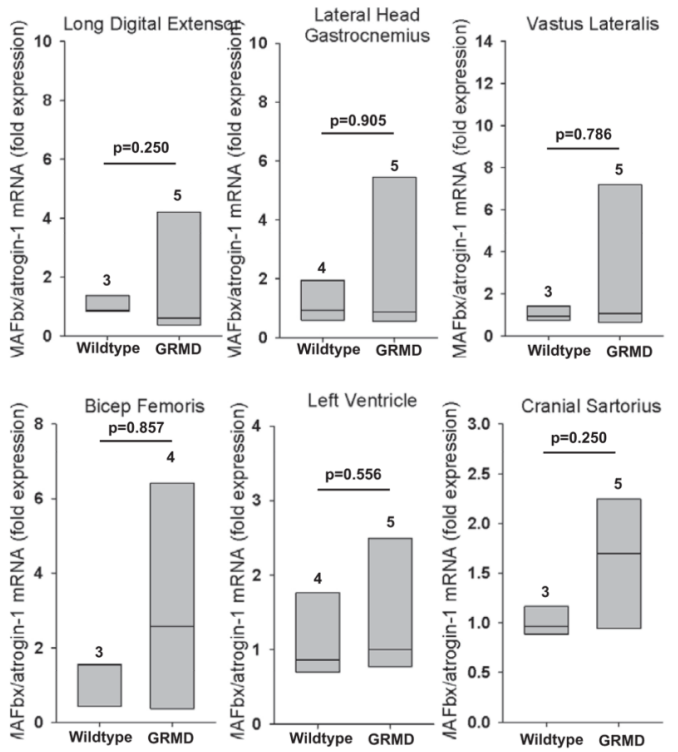

\section{Murine double minute 2 (MDM2)}
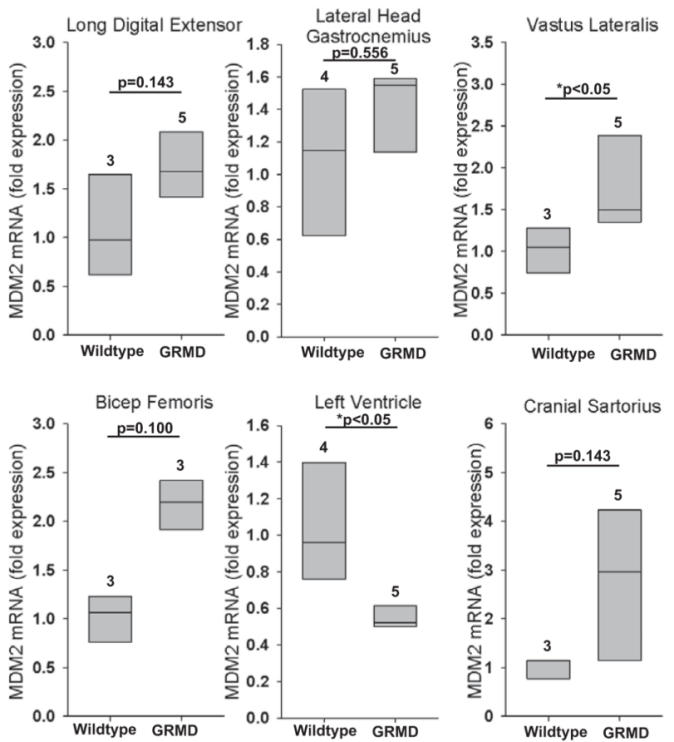

Figure 1. Ubiquitin ligase (E3) expression in golden retriever muscular dystrophy (GRMD) Quantitative mRNA expression analysis of the ubiquitin ligases (A) Muscle Ring Finger-1 (MuRF1), (B) Muscle F-box protein (MAFbx), (C) carboxyl terminus of Hsp70-interacting protein (CHIP), and (D) Mouse double minute-2 (MDM2) in GRMD lateral digital extensor, the lateral head of the gastrocnemius, vastus lateralis, biceps femoris, left ventricle, and cranial sartorius. mRNA expression is shown as the fold change compared to age-matched control animals. Data represent 3-5 dogs per group (outlined in Supplemental Table 3), as indicated above each vertical box plot. The vertical box plot presents the median $(50 \%$ percentile), indicated by the middle line inside the box, the $75 \%$ percentile indicated by the 
top of the box, and the $25 \%$ percentile indicated by the bottom of the box. A Rank-Sum test was used to determine the differences in mRNA expression. ${ }^{*} \mathrm{p} \leq 0.05$. 
A Ubiquitin
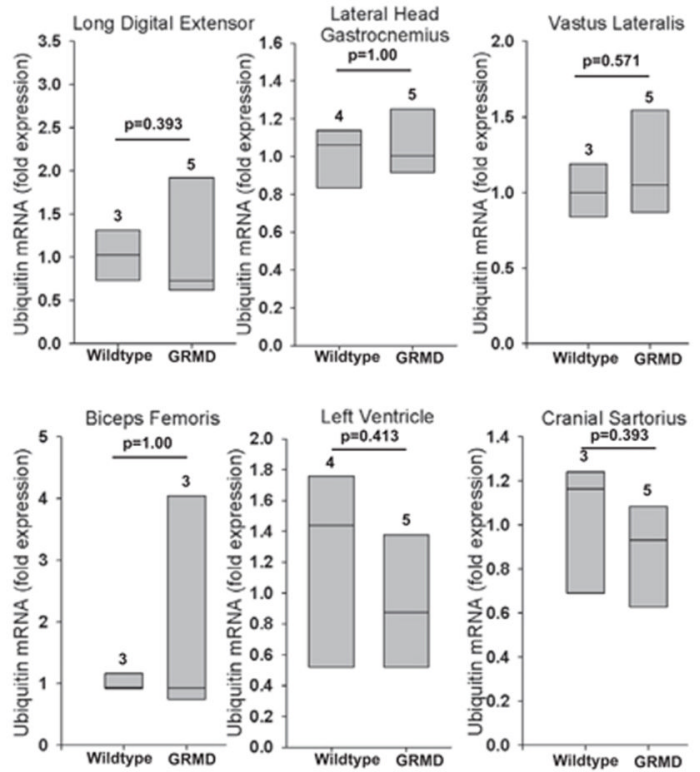

B Uncoordinated phenotype 4/5

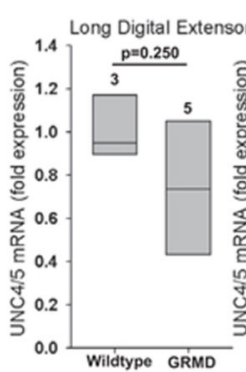

Lateral Head
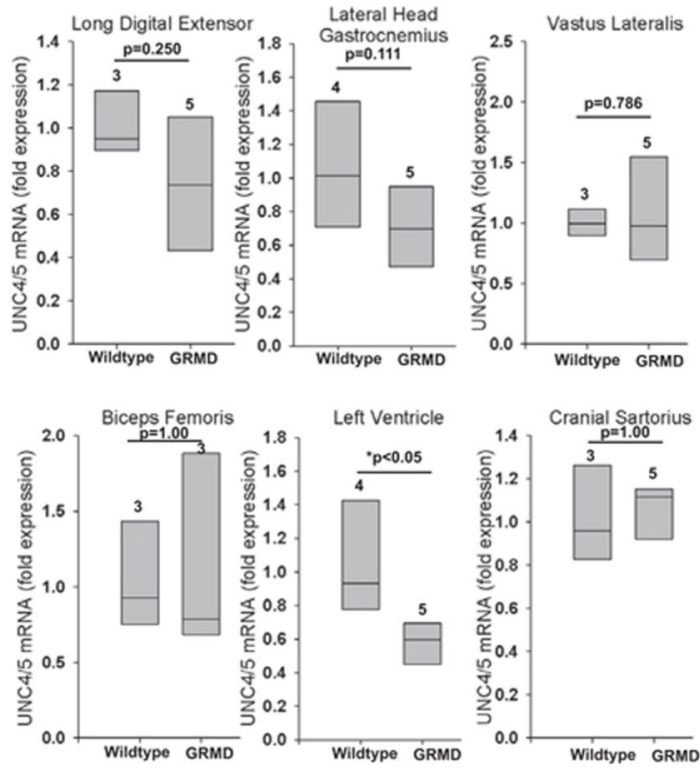

\section{Ubiquitin-like protein SUMO-1}
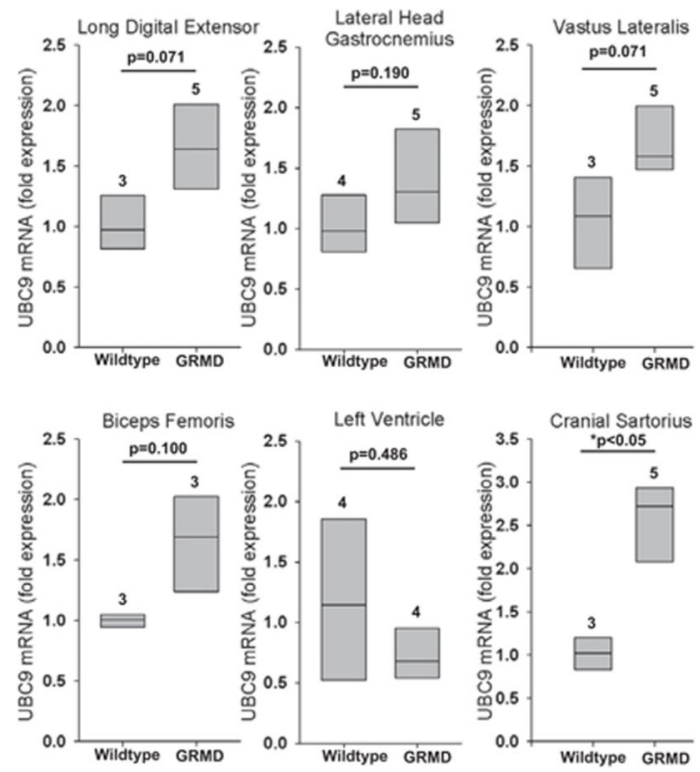

Figure 2. Expression of ubiquitin, UNC4/5, and the $\mathrm{E} 2$ ubiquitin conjugating enzyme UBC9 in GRMD skeletal muscle and heart

Quantitative mRNA expression analysis of (A) ubiquitin, (B) the protein chaperone $\mathrm{UNC} 4 / 5$, and (C) E2 UBC9 in the GRMD lateral digital extensor, the lateral head of the gastrocnemius, vastus lateralis, biceps femoris, left ventricle, and cranial sartorius. mRNA expression is shown as the fold change compared to age-matched control animals. Data represent 3-5 dogs per group (outlined in Supplemental Table 3), as indicated above each vertical box plot. The vertical box plot presents the median (50\% percentile), indicated by the middle line inside the box, the $75 \%$ percentile indicated by the top of the box, and the 
$25 \%$ percentile indicated by the bottom of the box. A Rank-Sum test was used to determine the differences in mRNA expression. ${ }^{*} \mathrm{p} \leq 0.05$. 


\section{A Proteasome subunit, alpha-type 6}
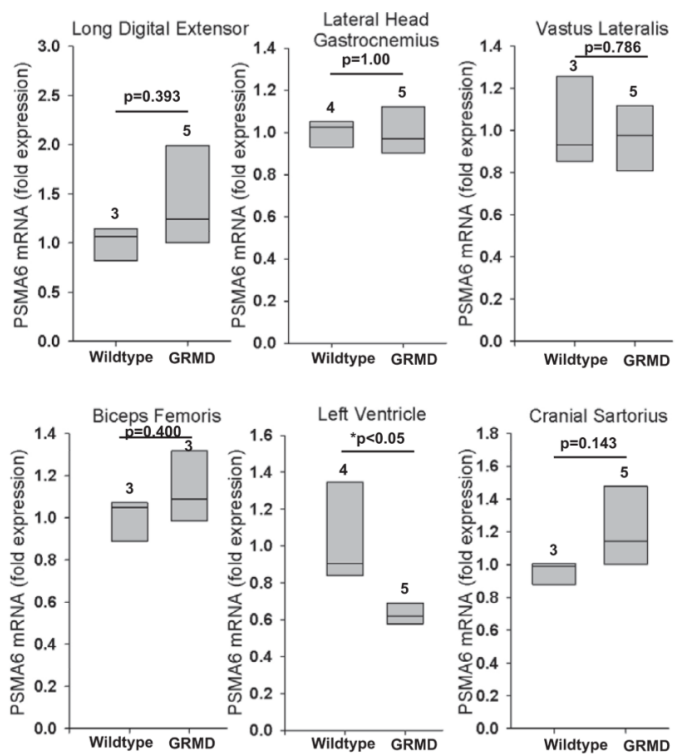
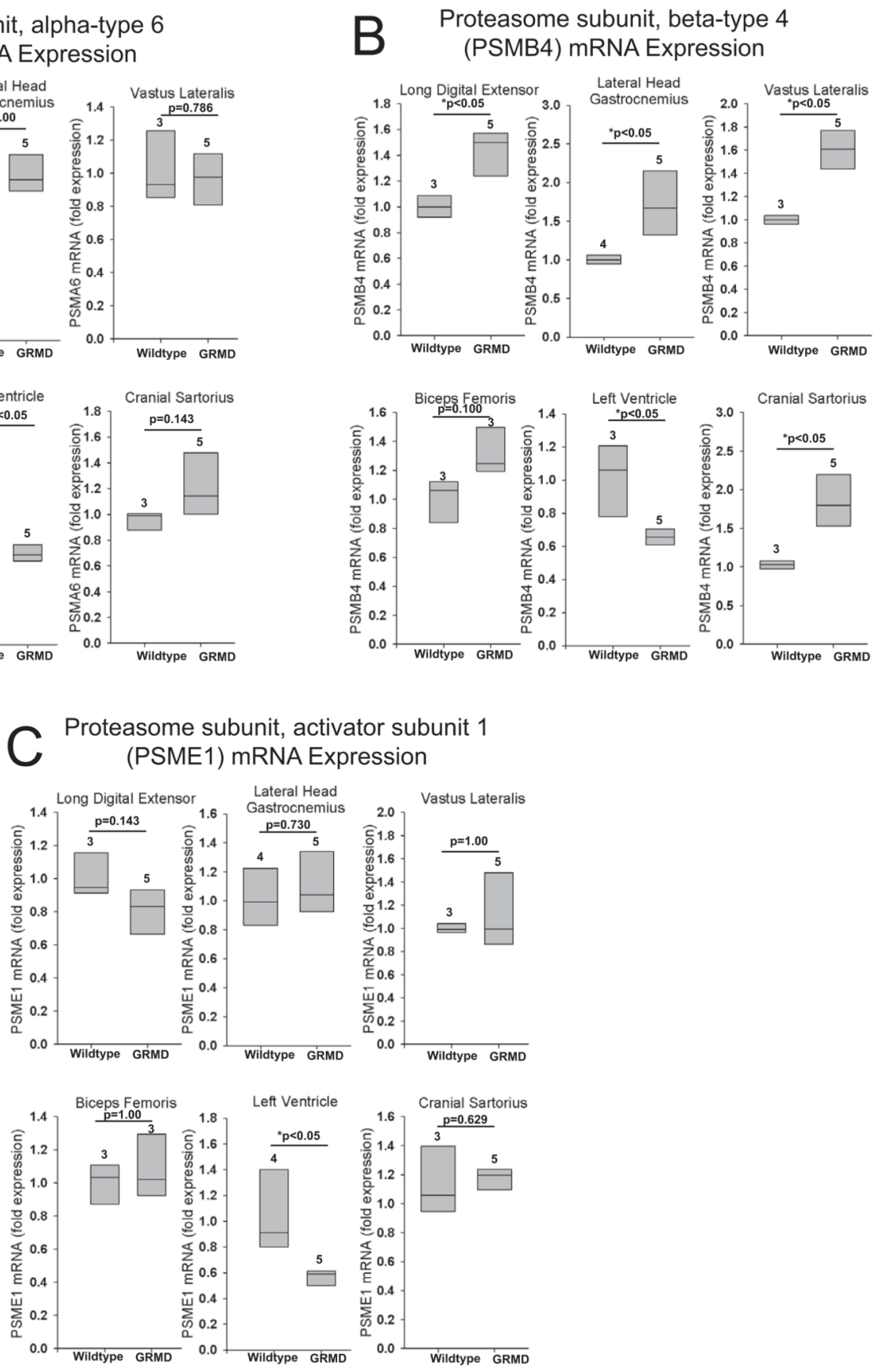

Figure 3. Proteasome subunit expression in GRMD skeletal muscle and heart Quantitative mRNA expression analysis of the proteasome subunits (A) PSMA6, (B) PSMB4, and (C) PSME1 in GRMD long digital extensor, lateral head of the gastrocnemius, vastus lateralis, biceps femoris, left ventricle, and cranial sartorius. mRNA expression is shown as the fold change compared to age-matched control animals. Data represent 3-5 dogs per group (outlined in Supplemental Table 3), as indicated above each vertical box plot. The vertical box plot presents the median (50\% percentile), indicated by the middle line inside the box, the $75 \%$ percentile indicated by the top of the box, and the $25 \%$ percentile indicated by the bottom of the box. A Rank-Sum test was used to determine the differences in mRNA expression. ${ }^{*} \mathrm{p} \leq 0.05$. 
A
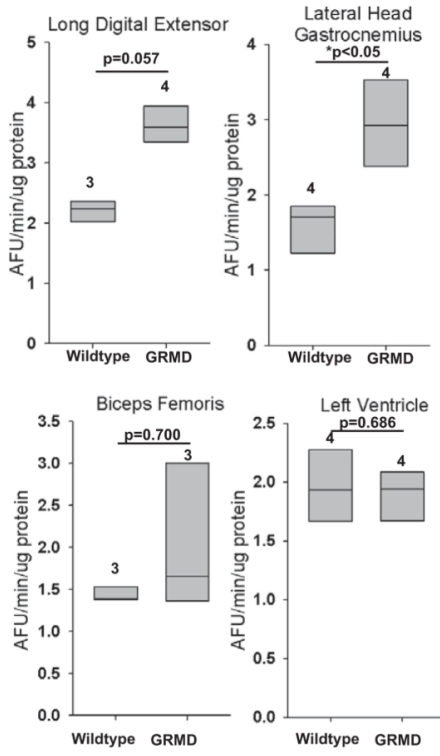

Trypsin-like Activity
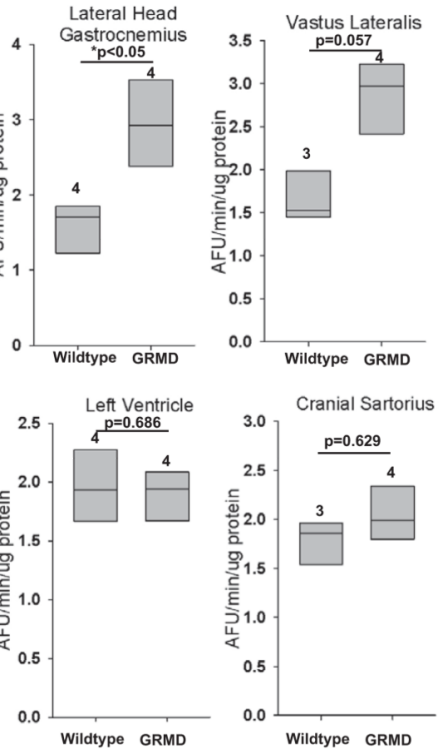

B

Caspase-like Activity
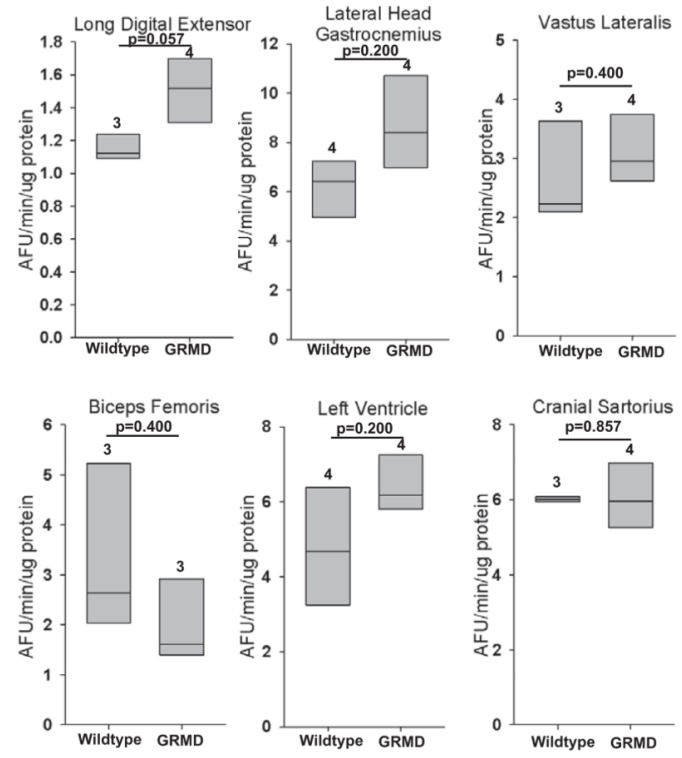

\section{Chymotrypsin-like Activity}
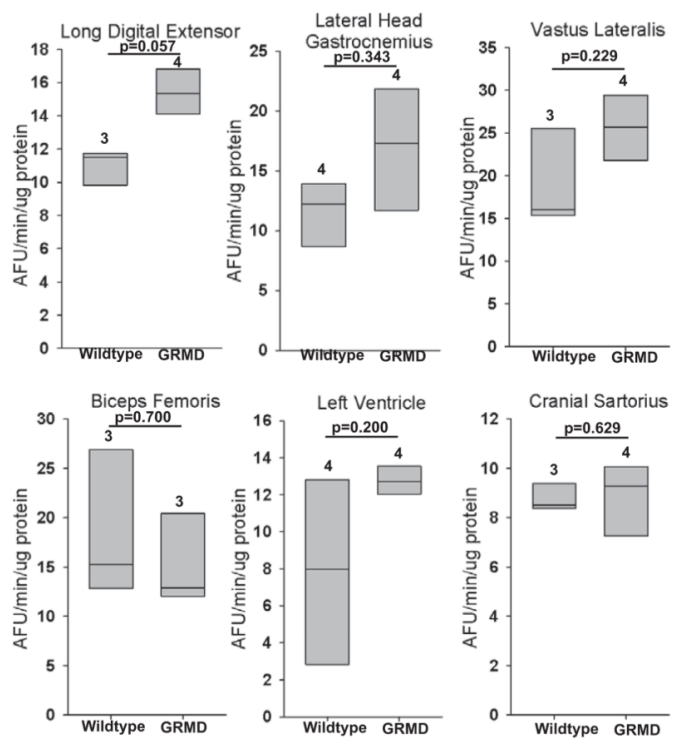

Figure 4. Muscle specific proteasome activities in GRMD

(A) Trypsin-like, (B) caspase-like, and (C) chymotrypsin-like activities in GRMD long digital extensor, lateral head of the gastrocnemius, vastus lateralis, biceps femoris, left ventricle, and cranial sartorius. Proteasome activities are presented as arbitrary fluorscent units (AFU). Data represent 3-5 dogs per group (outlined in Supplemental Table 3), as indicated above each vertical box plot. The vertical box plot presents the median (50\% percentile), indicated by the middle line inside the box, the $75 \%$ percentile indicated by the top of the box, and the $25 \%$ percentile indicated by the bottom of the box. A Rank-Sum test was used to determine the differences in proteasome activity. ${ }^{*} \mathrm{p} \leq 0.05$. 
A Calpain 1 mRNA Expression
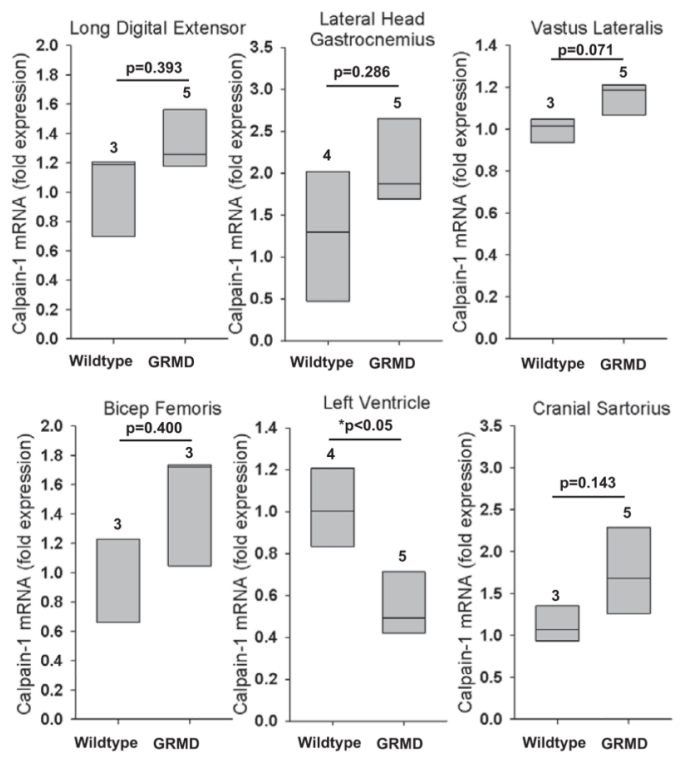

B Calpain 2 mRNA Expression
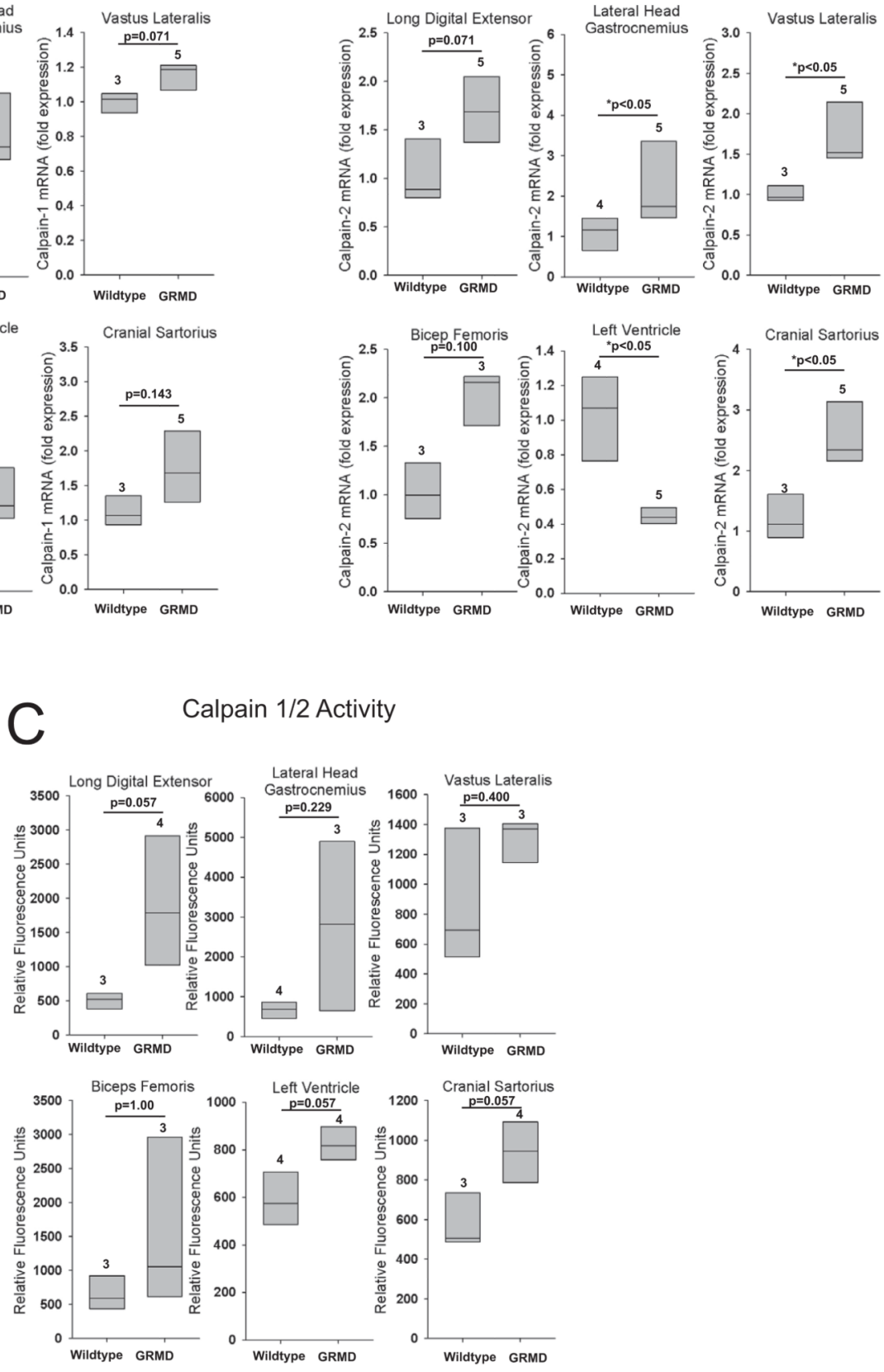

Figure 5. Muscle specific calpain1/2 activities in GRMD

Quantitative mRNA expression analysis of (A) calpain 1, and (B) calpain 2 in GRMD long digital extensor, lateral head of the gastrocnemius, vastus lateralis, biceps femoris, left ventricle, and cranial sartorius. Expression levels are presented as a percentage of agematched controls. (C) Calpain 1/2 activity determined by a fluorimetric based-assay on GRMD long digital extensor, lateral head of the gastrocnemius, vastus lateralis, biceps femoris, left ventricle, and cranial sartorius. mRNA expression is shown as the fold change compared to age-matched control animals. Calpain $1 / 2$ activity is presented as the relative fluorometric units. Data represent 3-5 dogs per group (outlined in Supplemental Table 3), as indicated above each vertical box plot. The vertical box plot presents the median (50\% 
percentile), indicated by the middle line inside the box, the $75 \%$ percentile indicated by the top of the box, and the $25 \%$ percentile indicated by the bottom of the box. A Rank-Sum test was used to determine the differences in mRNA expression and calpain $1 / 2$ activity. $* \mathrm{p} \leq 0.05$. 
苛苛

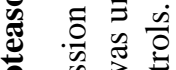

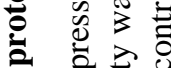

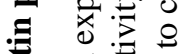

范导

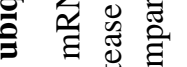

Ð

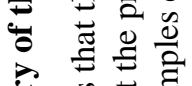

记苛芯

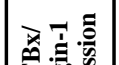




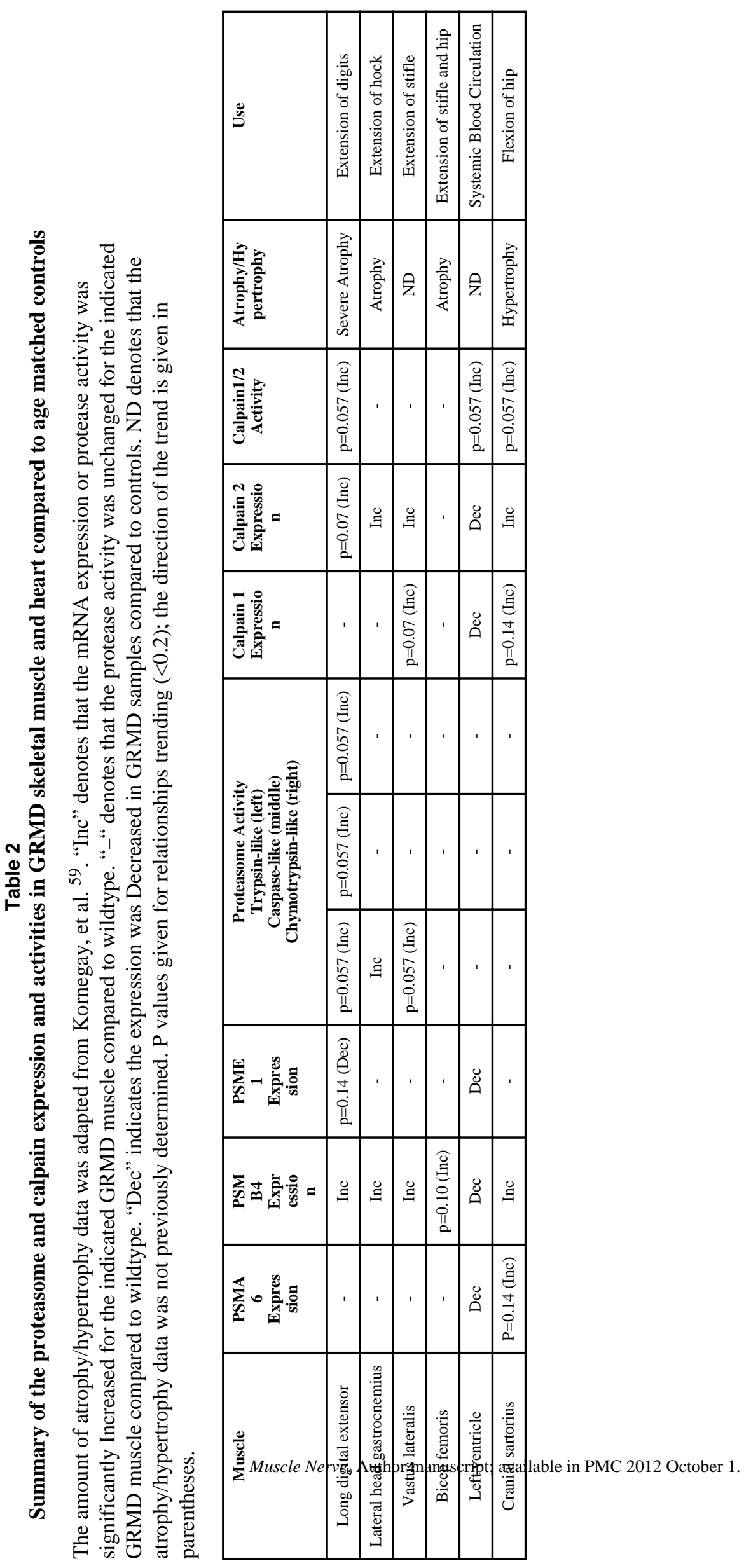

